\title{
Kripke e o Problema da Mente-Corpo*
}

\section{João Branquinho}

As seguintes teses acerca de três formas de identidade psicofísica dão-nos três formas relativamente independentes de materialismo acerca do mental: a) identidade de substâncias. A substância que tem atributos mentais, a mente, aquilo que satisfaz frases abertas como 'x está a pensar no Ser', é identificada com a substância que tem atributos fisicos, o corpo, aquilo que satisfaz frases abertas como ' $x$ tem $1 \mathrm{~m} 80 \mathrm{~cm}$ de altura'. b) identidade de propriedades (identidade tipo-tipo). Cada propriedade mental ou tipo de estado mental, a propriedade expressa por frases abertas como 'x é uma dor', é idêntica a uma certa propriedade física ou tipo de estado do cérebro, a propriedade expressa por frases abertas como ' $x$ é um disparar de tais e tais neurónios'. Tipos mentais são objectos repetíveis, exemplificáveis. c) identidade de particulares (identidade especimen-especimen). Cada estado ou evento mental particular, aquilo que satisfaz frases abertas como ' $x$ é uma dor', é idêntico a um certo estado ou evento físico no cérebro, aquilo que satisfaz frases abertas como ' $x$ é um disparar de tais e tais neurónios'. Eventos mentais particulares são objectos irrepetiveis, não exemplificáveis.

São famosos os argumentos aduzidos por Saul Kripke, nas últimas páginas de Naming and Necessity (Kripke 1980: 144-55), contra cada uma dessas variedades de materialismo. Todavia, a apreciação do valor desses argumentos tem sido notoriamente assimétrica. Em muita da literatura filosófica mais recente há um contraste entre, de um lado, o valor atribuído aos argumentos contra o materialismo tipo-tipo, os quais são tidos como poderosos e baseados em intuições sólidas, e, do outro, o valor atribuído aos argumentos contra o materialismo especimen-especimen, acerca dos quais existe a convicção generalizada de que são inconclusivos e baseados em intuições frágeis. No interior do campo naturalista, podemos encontrar essa convicção em muitos dos actuais defensores do dualismo acerca de tipos, uma doutrina naturalmente combinada com o monismo acerca de particulares. Exemplos desse cepticismo em relação aos argumentos kripkeanos contra as identidades psicofisicas de particulares podem ser encontrados em trabalhos recentes de David Chalmers (Chalmers 1996), Thomas Nagel (Nagel 2000), Joseph Almog (Almog 1991, 1996, 2002), Joseph Levine (Levine 2001), e outros.

Não estou, no entanto, convencido de que tal cepticismo seja justificado. Quero re-avaliar os argumentos kripkeanos contra o materialismo especimen-especimen e mostrar, pelo menos, que não é líquido que eles não sejam procedentes. A tese deste ensaio é de natureza condicional: se os argumentos de inspiração kripkeana contra o materialismo tipo-tipo forem vistos como convincentes, se as intuições cartesianas que os suportam forem tidas como sólidas, então não há qualquer razão para não dizer o mesmo dos argumentos correspondentes contra o materialismo especimen-especimen; todavia, não se segue que um modus ponens possa ser executado sobre esta tese condicional, pois suspendo o juizo sobre a proposição antecedente. Começo por introduzir com algum detalhe os argumentos kripkeanos contra o materialismo especimen-especimen. Critico em seguida certas objecções centrais erguidas contra eles, sobretudo 
as oriundas de posições naturalistas nas quais é rejeitada a identidade de tipos mentais e físicos, ou mesmo a superveniência lógica daqueles sobre estes. Finalmente, examino algumas das consequências que adviriam da hipótese de particulares mentais e físicos serem de facto distintos; em especial, tento responder à seguinte pergunta, embaraçosa para quem quer que defenda essa não identidade. Se particulares mentais não são determinados eventos complexos específicos no cérebro, então afinal o que são? Como é habitual nas discussões na área, foco a minha atenção em estados e eventos que povoam a consciência fenoménica, em especial dores.

\section{OArgumento}

Seja $a$ um evento mental particular, e.g. uma dor específica que uma pessoa, digamos Kripke, tem numa determinada ocasião. E $b$ um certo evento específico no seu cérebro, e.g. um disparar particular de certos neurónios que ocorre naquela ocasião e cujo tipo a ciência descobriu estar sistematicamente correlacionado com o tipo de $a$ (de acordo com a ficção filosófica, $b$ é um disparar de fibras-C). Para o materialismo especimen-especimen, identidades como $a=b$ são verdadeiras. O argumento é então o seguinte modus tollens:

(PI) Se $a$ é idêntico a $b$ então, $a$ é necessariamente idêntico a $b$

(P2) É metafisicamente possível que $a$ seja distinto de $b$

(C) Logo, $a$ é distinto de $b$

(PI) é um caso particular da tese da necessidade da identidade: identidades verdadeiras não o são apenas contingentemente. Se os designadores utilizados forem designadores flexíveis dos eventos $a$ e $b$, e.g. 'A dor favorita de Kripke' e 'O evento registado em tal ocasião pela técnica da ressonância magnética', então o argumento deve ser tomado como de re, sendo dado às descrições intervenientes âmbito longo sobre os operadores modais. Assim, (PI), se verdadeira, é-o independentemente de qualquer modo particular de identificação dos eventos $a$ e $b$; a tese da rigidez dos designadores utilizados é deste modo inessencial ao argumento. (P2) é a premissa fundamental, aquela que é tipicamente rejeitada pelos críticos. As seguintes considerações, baseadas em intuições cartesianas familiares acerca das relações entre o mental e o físico, são usadas para a estabelecer. Considere-se um mundo possível $m$ onde o evento físico $b$ ocorre (e assim existe), mas onde Kripke não sente na ocasião qualquer dor. Esta é uma situação imaginável ou concebível. Logo, o evento mental (de dor) $a$ não pode ocorrer, e assim não pode existir, em $m$ na ocasião. Mas então em $m$ não se tem de todo $a=b$, pela simples razão de que $b$ existe nesse mundo e $a$ não. (P2) segue-se assim da seguinte proposição:

$(P 2)^{*}$ É metafisicamente possível que $b$ exista e $a$ não exista.

(Kripke admite também a possibilidade conversa: um mundo onde o evento de dor $a$ ocorre numa certa ocasião, mas onde o cérebro do sujeito não está na ocasião na configuração específica $b$. Esta seria igualmente uma maneira de estabelecer (P2). Todavia, por razões indicadas mais à frente, trata-se de uma pretensão mais controversa).

Há uma réplica imediata ao argumento cujo exame é instrutivo, pois permite trazer à superfície uma suposição crucial do qual ele depende. Pode-se objectar que há uma falácia no raciocínio: do facto de, em $m$, o evento físico $b$ ocorrer sem que o sujeito sinta qualquer dor, infere-se que o evento $a$ não ocorre, e logo que $a$ não existe em $m$. Esta inferência é um non-sequitur, pois a seguinte possibilidade é ignorada: o evento $a$ ocorrer, e assim existir em $m$, mas não ser uma dor em $m$. Se uma tal possibilidade é admitida, $m$ não é um mundo onde o evento físico $b$ exista sem o evento $a$. Antes, é um mundo onde $b$ existe (e pertence a um certo tipo físico) e $a$ (ou seja, $b$ ) existe mas não é uma dor. $(P 2) *$ é deste modo tornada falsa e o materialismo especimen-especimen vindicado: cada particular mental é idêntico a um particular físico, mas estas identidades são necessárias e não contingentes.

O contra-argumento de Kripke é o seguinte. A réplica depende da ideia de que a propriedade de ser uma dor é uma propriedade continger ée de eventos actuais de dor: 
um evento que exemplifica (numa dada ocasião) no mundo actual a propriedade de ser uma dor pode não a exemplificar (nessa ocasião) em pelo menos um mundo possível onde ocorra. Com efeito, se, como o materialista quer, $a$ (ou seja, $b$ ) pode ocorrer em $m$ sem ser uma dor, então temos um evento, $a$ (ou seja, $b$ ), o qual exemplifica a propriedade de ser uma dor no mundo actual mas já não a exemplifica em $m$. Todavia, a tese da contingência é intuitivamente implausível. Ela colide com a nossa intuição de que ser uma dor é uma propriedade essencial de qualquer dor: se um dado evento é na realidade uma dor, então é-o em qualquer mundo possível em que ocorra. Por conseguinte, o argumento kripkeano exige, relativamente à sua premissa (P2), o seguinte género de princípio essencialista:

(E) Se $x$ é uma dor, então, necessariamente, se $x$ existe, então $x$ é uma dor

No modo formal, esta é a tese de que termos mentais como 'dor' são rígidos. Um predicado ' $P$ ' aplica-se rigidamente a um item $x$ quando ' $P$ ' se aplica a $x$ em qualquer mundo possível em que $x$ exista. Por exemplo, o predicado ‘é um filósofo' não se aplica rigidamente a Sócrates, mas o predicado 'é uma pessoa' presumivelmente sim. A cogência do argumento contra o materialismo especimen-especimen depende então, em parte, da plausibilidade da tese da rigidez de predicados mentais, ou da sua contraparte no modo material, a tese (E).

Existe outro género de suposição geral que é precisa para fazer correr o argumento. Ela pode ser identificada ao considerarmos as razões invocadas para aceitarmos a premissa $(P 2) *$. Por que é que é possível que o evento físico $b$ ocorra sem que ocorra qualquer dor? Em primeiro lugar, como sugerido, a resposta é que essa é uma situação concebível. Recorre-se aqui ao seguinte princípio geral que sanciona inferências do concebível para o possível:

(C) Se uma situação $s$ é concebível, então $s$ é metafisicamente possível.

(C) parece ser duvidoso, mesmo à luz de padrões kripkeanos. Voltaremos daqui a pouco a ele; para já, regressemos à nossa pergunta acima. Em segundo lugar, é concebível a ocorrência do evento físico $b$ sem qualquer ocorrência de dor porque é concebível uma situação em que uma certa configuração específica do cérebro não é sentida como dor, no sentido de não ter as propriedades intrínsecas subjectivas que são características da experiência de dor, os qualia associados, a fenomenologia da dor. A presunção é a de que a fenomenologia da dor, o sentir da dor, é uma propriedade não contingente de qualquer evento específico de dor. É assim assumido mais um princípio essencialista acerca da consciência fenoménica:

(F) Se $x$ é uma dor, então, necessariamente, se $x$ existe, então $x$ é sentida como dor.

Como, na situação descrita, $b$ existe mas carece da fenomenologia da dor, segue-se que $b$ não é uma dor nessa situação (apesar de $b$ ser, por hipótese, uma dor na situação actual), e logo não há nessa situação qualquer ocorrência do evento mental $a$ (assumindo o outro princípio essencialista, (E)).

Uma versão mais simples do argumento, na qual são utilizadas exactamente as mesmas suposições gerais, é formulada em termos de certas propriedades modais de eventos e consiste numa aplicação da discernibilidade de distintos. Seja $F$ a propriedade que um evento tem quando é essencialmente uma dor, a propriedade modal de ser uma dor em qualquer situação possível em que ocorra. Então o argumento é o seguinte:

(P3) $a$ tem $F$

(P4) $b$ não tem $F$

(C) Logo, $a$ e $b$ são distintos

(P3) é uma consequência da tese essencialista (E). (P4) exprime o facto de a propriedade de ser uma dor ser apenas uma propriedade contingente do evento físico $b$, e segue-se grosso modo da tese essencialista $(F)$.

Há aqui subjacente a inferência supra mencionada do concebível para o possível. Examinemo-la. Suponhamos que é concebível um evento particular exemplificar a propriedade de ser uma estimulação das fibras- $C$ sem exemplificar a propriedade de ser uma dor. Pode-se objectar que daí não se segue que tal situação seja metafisicamente 
possivel, que ela apenas parece sê-lo, que é de facto metafisicamente impossível. Afinal, é concebível que a água não seja $\mathrm{H}_{2} 0$; todavia, se Kripke está certo, essa é uma situação metafisicamente impossível. Concedendo que situações daquelas são metafisicamente impossíveis, e se quisermos ainda manter o princípio $(C)$, resta perguntarmos porque é que, no entanto, elas parecem ser concebíveis? Porque é que parece ser concebível que a estimulação das fibras-C ocorra sem que a dor ocorra? Kripke argumenta por reductio que uma explicação adequada das alegadas ilusões de contingência não está disponível no domínio da consciência fenoménica. Vejamos. O proponente da necessidade das identidades psicofisicas de particulares teria de explicar porque é que a seguinte afirmação é verdadeira:

\section{(1) A seguinte situação parece ser concebível: $x$ é uma estimulação das fibras-C e $\mathbf{x}$ não é uma dor.}

O único tipo de explicação disponivel seria o seguinte. As razões pelas quais (1) é verdadeira são análogas às razões pelas quais (2) é verdadeira:

(2) A seguinte situação parece ser concebível: $x$ é calor e $x$ não é uma agitação das moléculas.

(2) é verdadeira porque a situação aparentemente imaginada é confundida com uma situação diferente, mas qualitativamente idêntica do ponto de vista epistémico, a qual é de facto metafisicamente possível. Em particular, (2) é verdadeira porque (3) é verdadeira:

(3) A seguinte situação é metafisicamente possível: $x$ causa em nós a sensação de calor e $\boldsymbol{x}$ não é uma agitação das moléculas.

Por analogia, ter-se-ia então o seguinte: (1) é verdadeira porque a situação aparentemente imaginada é confundida com uma situação diferente, mas qualitativamente idêntica do ponto de vista epistémico, a qual é de facto metafisicamente possível. Em particular, (1) é verdadeira porque (4) é verdadeira:

(4) A seguinte șituação é metafisicamente possível: $x$ é uma estimulação das fibras-C e $x$ não é sentida como dor.

Mas então, dada a tese essencialista $(F)$, a seguinte conclusão seguir-se-ia:

(5) A seguinte situação é metafisicamente possível: $x$ é uma estimulação das fibras-C e $\boldsymbol{x}$ não é uma dor.

(5) é claramente inconsistente com a suposição de que as identidades psicofísicas não são contingentemente verdadeiras, sendo assim obtida a reductio desejada.

Há uma diferença importante entre o caso mental, ou pelo menos o caso da consciência fenoménica (a dor), e o caso não mental (o calor). Neste há lugar para um hiato entre a realidade, o fenómeno (o calor), e a aparência, a sensação por ele causada em nós. Naquele não há lugar para hiatos desses, uma vez que o fenómeno é ele próprio a sensação. No primeiro caso, apenas parece ser concebível o calor sem a agitação das moléculas, pois podemos sempre dizer que aquilo que é de facto concebível é algo diferente: o calor sem a sensação de calor. No segundo caso, não é verdade que apenas pareça ser concebível o physicalium sem a experiência. Esta é uma situação de facto concebível, pois não podemos de todo dizer aqui que aquilo que é concebido é algo diferente: a experiência sem a aparência da experiência, a dor sem o sentir da dor; à luz de $(F)$, necessariamente, se há a experiência, então há a aparência de experiência. Kripke opera com uma distinção entre aparência e realidade na própria esfera do imaginável ou concebível. Nem tudo aquilo que parece ser concebível é de facto concebível: há coisas que apenas parecem ser concebíveis. Em geral, se uma situação é tal que apenas parece ser concebível, uma explicação desta mera aparência tem de ser encontrada. No caso das identidades necessárias empíricas, ela está disponível. No caso das alegadas identidades necessárias psicofísicas, não está. Por conseguinte, no domínio da consciência fenoménica, a inferência do concebível para o possível é executável com inteira segurança. 


\section{As Objecções}

É possível discernir duas grandes linhas de crítica ao argumento kripkeano. $\mathrm{O}$ alvo de ataque de ambas é a premissa $(P 2)^{*}$, a ideia de que $b$ (o evento cerebral) poderia ocorrer sem $a$ (a experiência). A primeira provém de posições tradicionais nas quais é defendida a identidade psicofísica de tipos; estas identidades são, no entanto, tidas como meramente contingentes (apesar de poderem ser combinadas com identidades psicofísicas necessárias de particulares). A segunda provém de posições mais recentes nas quais é rejeitada a identidade psicofísica de tipos e adoptada alguma forma de dualismo de propriedades físicas e mentais, o qual é também combinado com identidades psicofísicas necessárias de particulares. Concentro a minha atenção nestas últimas posições, nas quais se faz uso de intuições modais cartesianas análogas às utilizadas por Kripke e nas quais julgo ser capaz de discernir certas tensões internas. Convém, porém, dar antes uma breve vista de olhos pelas posições do primeiro género.

Nestas posições é caracteristicamente rejeitada a tese da rigidez de predicados mentais, ou a tese essencialista $(E)$, e logo a premissa $(P 2) *$. A mais conhecida é a variedade de funcionalismo proposta por David Lewis, à qual podemos chamar funcionalismo analitico (Lewis 1994). Neste ponto de vista, um estado mental é analiticamente identificado com o seu papel causal, a rede de conexões causais que tipicamente se verificam entre o estado em questão e input proveniente do meio-ambiente, entre o estado em questão e outros estados mentais, e entre o estado em questão e output comportamental. O que é importante para os nossos efeitos é que a propriedade de um certo estado (o qual pode ser um estado do cérebro) ter um determinado papel causal é uma propriedade contingente do estado em questão, uma propriedade que este tem mas poderia não ter. Um dado estado do cérebro, o qual tem no mundo actual a propriedade de ter o papel causal característico da dor, pode perfeitamente não ter essa propriedade. Há assim uma situação possível onde o estado em questão não é uma dor; isto porque é analítico que um estado $x$ é uma dor se, e só se, $x$ tem o papel característico da dor. Por conseguinte, no nosso caso, há uma situação possível na qual o evento físico $b$ (ou $a$ ), uma dor no mundo actual, não é uma dor. Enquanto que é analítico que $x$ é uma dor se, e só se, $x$ tem o papel causal característico da dor, é contingente e a posteriori que $x$ tem esse papel causal se, e só se, $x$ é um disparar de tais e tais neurónios (é contingente e a posteriori qual o estado físico que desempenha o papel causal em questão); logo, é contingente e a posteriori que $x$ é uma dor se, e só se, $x$ é um disparar de tais e tais neurónios. Como o conceito de um estado mental é reduzido ao conceito de um determinado papel causal, a outra tese essencialista de Kripke, a tese $(F)$, é também rejeitada neste ponto de vista (supondo que não há quaisquer conexões conceptuais apropriadas entre papel causal e fenomenologia).

São sobejamente conhecidas as dificuldades do funcionalismo analítico, tal como identificadas por Ned Block (Block 1994), Nagel (Nagel 2000), e outros. Não vamos aqui entrar nos detalhes. Basta observar que a mais notória dessas dificuldades consiste precisamente no facto de a teoria não ter aparentemente recursos para acomodar satisfatoriamente o domínio da consciência fenoménica, deixando necessariamente de fora as propriedades fenomenológicas intrínsecas e essenciais de dores, emoções, experiências visuais, orgasmos, e outros estados mentais conscientes. Por outro lado, a teoria tem a consequência, indesejável para muitos, de tornar propriedades gerais como a própria propriedade de ser um estado mental numa propriedade contingente de estados mentais dados.

Consideremos agora as posições do segundo género. As ideias de Chalmers são delas representativas. Em The Conscious Mind Chalmers argumenta contra a superveniência lógica do mental sobre o físico, e logo contra o materialismo tipo-tipo (Chalmers 1996: 146-50). Desempenha um papel crucial nesses argumentos a hipótese de um mundo zombie, uma situação na qual há criaturas (zombies) que são fisicamente indiscerníveis de nós mas que não têm consciência. Num mundo zombie são assim exemplificados estados neurofisiológicos, por exemplo a estimulação das fibras-C, sem 
que os correspondentes estados fenoménicos, a dor, o sejam. Se tais situações são de facto possíveis, então são contra-exemplos à superveniência lógica, grosso modo a tese de que quaisquer mundos logicamente possíveis que sejam indiscerníveis quanto à exemplificação de propriedades físicas são indiscerníveis quanto à exemplificação de propriedades mentais. A intuição cartesiana utilizada por Kripke, a intuição modal de que o physicalium é concebível sem a fenomenologia, e logo sem a experiência, está manifestamente subjacente à hipótese de um mundo zombie. Todavia, Chalmers rejeita o argumento kripkeano contra o materialismo especimen-especimen. Há três pretensões principais no seu contra-argumento. Primeiro, há a pretensão de que o argumento kripkeano depende de intuições essencialistas duvidosas e dificeis de justificar, as quais envolvem a identidade transmundial de estados físicos (ou mentais) particulares. Quando Kripke nos convida a considerar a possibilidade de o evento físico $b$ ocorrer sem dor, aquilo que nós somos convidados a considerar é um mundo possível não actual onde numericamente o mesmo evento específico que ocorre no mundo actual ocorre aí sem dor. Chalmers vê com suspeita intuições destas acerca do que é que conta como o mesmo estado físico (ou mental) particular de mundo para mundo. $\mathrm{O}$ argumento dos zombies não depende de tais intuições, pois está formulado, não em termos de identidade de estados, mas apenas em termos de indiscernibilidade ou semelhança. Em segundo lugar, apoiando-se em observações de McGinn e outros, Chalmers alega que há sempre a possibilidade de considerar a propriedade de ser uma dor, não apenas como uma propriedade essencial da experiência particular de dor $a$, mas também como uma propriedade essencial do evento cerebral $b$. Assim, a premissa (2)* - ou, equivalentemente, $(P 4)$ - seria rejeitada e o materialismo especimen-especimen estabelecido, sendo os eventos $a$ e $b$ estritamente identificados. Podemos considerar a propriedade de ser uma dor como uma propriedade meramente contingente de um estado físico do cérebro, da estimulação das fibras- $C$, mas apenas enquanto este for tomado como um tipo de estado; essa propriedade pode bem ser, no entanto, essencial a um estado especimen, designadamente $b$ (ou seja, $a$ ). Em terceiro lugar, há a pretensão análoga de que há sempre a possibilidade de considerar a fenomenologia da dor, não apenas como uma propriedade essencial da experiência particular de dor $a$, mas também como uma propriedade essencial do evento cerebral $b$. Podemos considerar a propriedade de ser sentida como dor como uma propriedade meramente contingente de um estado físico do cérebro, da estimulação das fibras- $\mathrm{C}$, mas apenas enquanto este for tomado como um tipo de estado; essa propriedade pode bem ser, no entanto, essencial a um estado especimen, designadamente $b$ (ou seja, $a$ ).

Apesar de engenhosos, tenho dúvidas quanto à força destes argumentos. Relativamente à primeira pretensão, não sou capaz de discernir diferenças substantivas entre, de um lado, as intuições modais cartesianas invocadas para admitir como concebível e metafisicamente possível um mundo zombie, e, do outro, as intuições modais invocadas por Kripke para admitir como concebível e metafisicamente possível uma situação na qual uma certa configuração específica actual do cérebro não é acompanhada por qualquer experiência. Não vejo qualquer diferença substantiva entre, de um lado, conceber uma situação na qual eventos cerebrais fortemente semelhantes aos meus ocorrem numa criatura (uma minha réplica zombie) sem que ela experiencie qualquer dor, e, do outro, conceber uma situação na qual os meus próprios estados cerebrais ocorrem sem que eu experiencie qualquer dor. Creio que há um nível básico no qual ambas as intuições podem ser vistas como igualmente sólidas, ou então como igualmente frágeis. É certo que a hipótese de um mundo zombie não depende da admissão de identidades transmundiais de estados. Todavia, supondo que o cepticismo de Chalmers não é acerca da identidade transmundial em geral, mas apenas acerca dessa variedade particular de identidades transmundiais, não vejo também grandes diferenças entre casos de identidade transmundial que envolvem estados físicos ou mentais específicos e casos de identidade transmundial que envolvem particulares de outro género, por exemplo pessoas, objectos materiais, e eventos. Há aqui igualmente um 
nível básico no qual ambas as intuições modais podem ser vistas como igualmente sólidas, ou então como igualmente frágeis. Não vejo qualquer diferença substantiva entre, de um lado, casos de identidade transmundial envolvidos em afirmações modais como 'Sócrates poderia não ter bebido a cicuta', 'Este jogo de futebol poderia ter durado menos tempo', ou 'Sócrates poderia não ter existido', e, do outro, casos de identidade transmundial envolvidos em afirmações modais como 'Esta dor poderia não ter sido tão incómoda', 'Esta dor poderia ter durado menos tempo', ou 'Esta dor poderia não ter existido'.

Quanto à segunda pretensão, também não a considero suficientemente justificada; e observações análogas poderiam ser feitas em relação à terceira pretensão. É necessário tornarmos preciso aquilo que Chalmers quer dizer quando diz que a propriedade de ser uma dor, apesar de não ser essencial à estimulação das fibras-C como tipo de estado neurofisiológico, é no entanto essencial a uma experiência particular de dor. Devemos distinguir entre duas maneiras de interpretar afirmações essencialistas da forma 'A propriedade de $\operatorname{ser} G$ é (respectivamente, não é) uma propriedade essencial de $F$ s', e.g. 'A propriedade de ser um mamífero é uma propriedade essencial de gatos'. Uma é a interpretação de dicto dada em (respectivamente em):

(6) O seguinte é necessário: para toda a coisa $x$, se $x$ é $F$ então $x$ é $G$

(6)* O seguinte não é necessário: para toda a coisa $x$, se $x$ é $F$ então $x$ é $G$.

A outra é a interpretação de re dada em (respectivamente em):

$x$ é $G$

(7) Para toda a coisa $x$, se $x$ é $F$ então o seguinte é necessário: se $x$ existe, então

(7)* Para toda a coisa $x$, se $x$ é $F$ então o seguinte não é necessário: se $x$ existe, então $x$ é $G$

Quando Chalmers diz que ser uma dor não é essencial à estimulação das fibras-C como tipo de estado, qual das duas interpretações é que ele tem em mente? Elas podem ser formuladas assim:

(8) O seguinte não é necessário: para todo o evento $x$, se $x$ é uma estimulação das fibras-C então $x$ é uma dor

(8)* Para todo o evento $x$, se $x$ é uma estimulação das fibras-C, então o seguinte não é necessário: se $x$ existe, então $x$ é uma dor

Ora, não pode ser a interpretação de re a intencionada, pois uma sua consequência lógica é precisamente a premissa $(P 2)$ do argumento kripkeano: o evento fisico $b$ poderia ter existido sem ser uma dor. Obviamente, Chalmers tem em mente a interpretação de dicto (8): ao contrário da afirmação de re, esta não está comprometida com identidades transmundiais alegadamente duvidosas entre estados físicos.

Todavia, julgo que há algumas dificuldades com esta proposta. Em primeiro lugar, por razões de simetria, o mesmo género de interpretação deveria ser aplicada a afirmações essencialistas da forma supra em que as letras $F$ e $G$ são substituídas pelo mesmo predicado. O que afirmações destas dizem é que a exemplificação de um tipo de coisas é essencial a cada uma das coisas desse tipo; por exemplo, a propriedade de ser um gato é essencial a cada gato. Mas se interpretarmos estas afirmações no sentido de dicto, ficamos com verdades lógicas da forma:

(9) O seguinte é necessário: para toda a coisa $x$, se $x$ é $F$ então $x$ é $F$.

Estas são verdadeiras para qualquer predicado inserido no lugar de $F$, e obtemos assim uma trivialização indesejável de algumas afirmações essencialistas. Chalmers quereria presumivelmente afirmar que a propriedade de ser uma dor é uma propriedade essencial da dor como tipo de estado. Ora, lendo isto de dicto, ficamos com a trivialidade: dor.

(10) O seguinte é necessário: para todo o evento $x$, se $x$ é uma dor, então $x$ é uma

Pelo contrário, se adoptarmos as leituras de re, ficamos com afirmações da forma (9)* Para toda a coisa $x$, se $x$ é $F$, então o seguinte é necessário: se $x$ existe então $x$ é $F$, 
as quais estão longe de ser triviais (não são certamente verdadeiras para qualquer predicado inserido no lugar de $F$ ). A contraparte de re de (10) é justamente a tese essencialista (E) usada no argumento kripkeano.

Por outro lado, noutros casos de essencialismo, designadamente os envolvidos nas necessidades empíricas, queremos de facto ter formulações de re. Quando dizemos que ser H20 é uma propriedade essencial da água, não queremos ser entendidos no sentido de estar a afirmar (ou apenas a afirmar) a de dicto

(11) O seguinte é necessário: para todo o líquido $x$, se $x$ é água então $x$ é $\mathrm{H}_{2} 0$;

queremos ser entendidos no sentido de estar a afirmar a de re

(11) * Para todo o líquido $x$, se $x$ é água, então o seguinte é necessário: se $x$ existe então $x$ é H20.

Não vejo qualquer razão para dar um tratamento diferente às afirmações essencialistas acerca de propriedades mentais.

Há ainda outro problema, mais sério, com a proposta de Chalmers. O materialista especimen-especimen pode bem contentar-se com as afirmações essencialistas de dicto, muito embora tal decisão tenha como consequência uma trivialização de alguns casos supostamente não triviais de essencialismo. Afinal, elas são suficientes para poder fazer correr o argumento dos zombies. Todavia, ele precisa de algo mais. Para bloquear o argumento kripkeano, ele precisa da afirmação essencialista de que a propriedade de ser uma dor é também uma propriedade essencial do evento cerebral $b$ (o qual é uma dor no mundo actual); ou seja, ele precisa da seguinte afirmação claramente de re:

(12) Necessariamente, se $b$ existe então $b$ é uma dor.

Mas uma identidade transmundial está aqui envolvida, pois a verdade de (12) exige que numericamente o mesmo evento cerebral (ou mental) possa ocorrer em mais do que um mundo possível. Para além disso, é razoável pensar que verdades como (12), se o forem, devem o facto de serem verdadeiras a outras verdades, a verdades mais gerais. Supondo que a propriedade de ser um cão é uma propriedade essencial de Rover, é razoável pensar que isso é o caso em virtude de (1) Rover exemplificar o tipo $\mathrm{CÃO}$ e (2) o tipo CÃO ser essencial a todos os seus exemplos. Analogamente, supondo que a propriedade de ser uma dor é uma propriedade essencial de $b$, é razoável pensar que isso é o caso em virtude de (1) $b$ exemplificar o tipo DOR e (2) o tipo DOR ser essencial a todos os seus exemplos. O princípio geral aqui operativo é então (2). Mas se (2) for lida de dicto, não é possível dele deduzir (12) (com a ajuda de (1)). (12) é derivável de (2) só se (2) for lida de re, ou seja, precisamente como a tese essencialista de Kripke (E). Por conseguinte, parece haver alguma tensão entre a pretensão materialista de que as afirmações essencialistas devem ser lidas de dicto, especialmente a afirmação de que a propriedade de ser uma dor não é essencial à estimulação das fibras-C como tipo, e a pretensão de que essa propriedade é no entanto essencial ao evento específico do cérebro $b$.

Termino a discussão das críticas ao argumento kripkeano com a consideração de uma objecção interessante feita por Almog no seu recente livro What Am I? (Almog 2002: 42-58). Almog defende que as premissas do argumento kripkeano são inconsistentes com uma importante tese essencialista subscrita pelo próprio Kripke, a tese da necessidade da origem. Esta é a tese de que a propriedade que um indivíduo $x$ tem de ter sido originado ou gerado por um indivíduo $y$, ou por um par de indivíduos $y$ e $z$, é uma propriedade essencial de $x$. Os exemplos famosamente discutidos por Kripke dizem respeito aos pais (biológicos) de uma pessoa: a propriedade de ter tido os pais que de facto teve é uma propriedade essencial de qualquer pessoa. Assim, supondo que a experiência de dor $a$ é de facto causalmente gerada pelo evento cerebral $b$, então a propriedade de ter sido gerado por $b$ é uma propriedade essencial de $a$ : necessariamente, se $a$ ocorre, então $a$ é gerado por $b$; segue-se que é impossível $a$ ocorrer sem que $b$ ocorra, o que contradiz as premissas do argumento kripkeano. Esta é, sem dúvida, uma objecção sérịa. Todavia, trata-se obviamente de uma objecção, não contra a versão particular do argumento kripkeano que introduzimos, a qual invoca apenas a possibilidade 
do physicalium ocorrer sem a experiência associada, mas contra uma sua variante, também defendida por Kripke, na qual é invocada a possibilidade diferente da experiência ocorrer sem o physicalium associado (o caso da dor incorpórea). Creio que a lição a tirar da objecção de Almog é a de que o argumento kripkeano contra o materialismo especimen-especimen não deve ser formulado em termos dessa variante. A versão por nós discutida é, no entanto, imune à objecção e é consistente com a doutrina da necessidade da origem. Aquilo com o qual ela é de facto inconsistente é com um princípio de superveniência lógica para particulares que tenha como consequência a necessitação da ocorrência do evento mental $a$ pela ocorrência do evento físico $b$ : qualquer mundo logicamente possível no qual $a$ ocorre é um mundo onde $b$ ocorre. Todavia, poderiamos sempre fazer para'particulares aquilo que Chalmers e outros fazem para propriedades: abandonar a superveniência lógica, substituindo-a pela relação mais fraca de superveniência natural. O princípio relevante de superveniência teria como consequência a necessitação nómica do evento mental $a$ pelo evento físico $b$ : qualquer mundo nomicamente possível no qual $a$ ocorre é um mundo onde $b$ ocorre; mas isto não é inconsistente com qualquer premissa da nossa versão do argumento kripkeano.

\section{O que é uma Experiência?}

Se estados mentais conscientes particulares, como dores específicas e orgasmos específicos, não são eventos complexos específicos no cérebro, então afinal o que são? Se o evento mental $a$ é algo distinto do evento cerebral correlacionado $b$, então o que é afinal $a$ ? Esta é uma questão que deve ser respondida por quem quer que esteja inclinado a rejeitar o materialismo especimen-especimen. As observações que se seguem constituem uma tentativa esboçada em direcção a uma resposta a tal questão.

Começo por notar que, felizmente, o caso de particulares mentais não é, a esse respeito, único. Problemas que estou inclinado a considerar como análogos a problemas daquele género têm sido discutidos, desde Aristóteles, acerca de inúmeros objectos materiais que povoam o nosso quotidiano: barcos, estátuas, mesas, pessoas, etc. Também aqui é pelo menos argumentável que há não identidades de particulares; e não identidades que são de algum modo problemáticas, pois os objectos supostamente não idênticos ocupam a mesma região espácio-temporal e partilham todas as propriedades manifestas. E também aqui, uma vez assumidas as não identidades, se fica com o problema de dizer o que é que são afinal as coisas assim vistas como distintas. Proponho-me explorar a analogia existente entre o caso dos objectos materiais comuns e o caso dos particulares mentais, e defender a ideia de que o padrão de explicação deve ser o mesmo para ambos os casos.

Para recorrer a um exemplo clássico, considere-se a estátua de bronze que tenho à minha frente e que representa o gigante Golias. Chamemos a esse objecto material ESTÁTUA. Consideremos agora a matéria particular, o pedaço específico de bronze, da qual esse objecto é composto. Chamemos-lhe BRONZE. Para dramatizar a situação, imaginemos que ambos ESTÁTUA e BRONZE começam a existir na mesma ocasião e cessam de existir na mesma ocasião (e ignoremos complicações derivadas das alterações e daa deteriorização a que o material está sujeito ao longo da sua existência). Tudo indica que ESTÁTUA não é nada mais do que BRONZE, que são objectos numericamente idênticos. Afinal, ocupam a mesma porção do espaço no decorrer de toda a sua existência, e têm em comum todas as propriedades que lhes estamos inclinados a atribuir. Todavia, argumentos modais poderosos podem ser construídos de modo a obter a conclusão contra-intuitiva de que ESTÁTUA e BRONZE são objectos distintos. Considere-se, por exemplo, a propriedade modal que uma coisa $x$ tem quando satisfaz a seguinte condição contrafactual: se o bronze se derretesse então $x$ deixaria de existir. BRONZE não tem esta propriedade, mas ESTÁTUA tem-na; ou seja, uma situação possível na qual o bronze se derrete é uma situação possível onde BRONZE continua a existir, mas ESTÁTUA não. Logo, BRONZE e ESTÁTUA não são idênticos. Suponhamos que argumentos deste género, os quais são surpreendentemente semelhantes aos 
argumentos modais anti-materialistas de Kripke, estabelecem de facto uma não identidade. Ficamos com o problema da identidade do objecto material relativamente à matéria do qual é feito. Se o objecto material que tenho diante de mim não é a matéria que o constitui, se é algo distinto do pedaço de bronze que também está diante de mim, então o que é afinal?

A sugestão que gostaria de fazer vai no sentido de considerar qualquer explicação que seja satisfatória para casos destes como uma explicação satisfatória para os casos de não identidades psicofísicas de particulares. A analogia consistiria em dizer que, do ponto de vista da sua identidade, a experiência de dor $a$ está para o estado neurofisiológico b que é o seu suporte material assim como a estátua de Golias está para o pedaço de bronze que a constitui. Mas há alguma explicação satisfatória para estes últimos casos? Uma possibilidade que me parece atraente é a teoria dos qua objectos proposta há já algum tempo por Kite Fine num pequeno artigo intitulado Acts, Events and Things (Fine 1982). Um qua objecto é uma espécie de fusão lógica de um objecto com uma propriedade. Dado um objecto $x$ e uma propriedade $P$ que $x$ tenha, podemos construir a partir desses dois objectos um terceiro objecto, um qua objecto, o qual consiste em tomar o objecto $x$ como se a propriedade $P$ lhe tivesse sido "colada". O resultado é $x$ qua $P$, um qua objecto. Por exemplo, dados Durão Barroso e a propriedade, que ele tem, de ser primeiro-ministro, temos o qua objecto Durão Barroso qua primeiro-ministro. Fine chama a $x$ a base do qua objecto $x$ qua $P$ e à propriedade $P$ a sua glosa. Qua objectos são definidos implicitamente por três princípios. O princípio da existência estabelece que $x$ qua $P$ existe num mundo $m$ e num tempo $t$ se e só se a base $x$ existe em $m, t$ e $x$ exemplifica a propriedade $P$ em $m, t$. O princípio da identidade estabelece que qua objectos $x$ qua $P$ e y qua $Q$ são idênticos somente se $x=y$ e $P=Q$; por outro lado, qualquer qua objecto $x$ qua $P$ é obviamente distinto da sua base $x$. Finalmente, o princípio da herança estabelece que, para qualquer mundo $m$ e tempo $t$, um qua objecto $x$ qua $P$ tem em $m, t$ todas as propriedades não formais que a sua base $x$ tem em $m, t$. A proposta de Fine em relação à identidade do objecto material que está à minha frente consiste então em identificá-lo com um certo qua objecto, aquele que consiste em glosar o pedaço de bronze com a descrição estátua de Golias; ou seja, o objecto ESTÁTUA é identificado com o qua objecto BRONZE qua estátua.

Proponho-me agora generalizar a teoria dos qua objectos ao caso das não identidades psicofísicas de particulares. Aliás, é conveniente observar que, supondo que tais particulares são eventos específicos, tal generalização é implicitamente sancionada pelo próprio Fine, pois ele considera que a sua teoria é aplicável a eventos. A ideia é identificar um estado mental específico, ao qual está associado um certo estado físico específico, com um determinado qua objecto; este é construído glosando o estado físico com certas propriedades mentais, propriedades constitutivas do tipo de estado mental exemplificado pelo estado mental em questão. Assim, o nosso evento mental $a$, a experiência particular de dor que Kripke sente numa certa ocasião, é identificado com algo como o qua objecto $b$ qua dor. A base $b$ é o evento específico que ocorre no cérebro de Kripke na ocasião, a glosa é uma propriedade mental apropriada que $b$ tem, a propriedade de ser uma dor. Por conseguinte, a dor é de facto um estado físico do cérebro, uma estimulação das fibras-C, mas é-o sob uma descrição mental. Naturalmente, em vez da glosa dor, poderiamos usar descrições mais finas para construir o qua objecto em questão. Se considerarmos que a fenomenologia da dor é tudo aquilo que precisamos para identificar dores como tal, podemos antes conceber a dor particular $a$ como o qua objecto $b$ qua Fen, em que Fen é uma descrição fenomenológica apropriada da dor.

Dada a não identidade de tipos mentais e físicos, as glosas dor e estimulação das fibras- $C$ não são idênticas, e assim, pelo princípio da identidade, os qua objectos $b$ qua dor (o evento mental) e $b$ qua estimulação das fibras- $C$ (o evento físico) são distintos. Note-se que as propriedades mencionadas no princípio da herança não podem ser propriedades formais, como por exemplo a propriedade da existência; caso contrário, 
do facto de a base $b$ existir num mundo seguir-se-ia que o qua objecto $b$ qua dor existe nesse mundo (o que pode não ser o caso). Por outro lado, o aparato conceptual dos qua objectos permite-nos captar a ideia de que o evento físico pode existir sem que o evento mental exista. Repare-se que, pelo princípio da existência, o qua objecto $b$ qua dor (o evento mental) existe num mundo somente se $b$ existe nesse mundo e $b$ é uma dor nesse mundo; por conseguinte, um mundo onde $b$ existe mas não é uma dor é um mundo onde o evento mental, o qua objecto $b$ qua dor, não existe, mas onde existe obviamente o evento físico, o qua objecto $b$ qua estimulação das fibras-C. As teses essencialistas utilizadas no argumento kripkeano são também facilmente representáveis. Por um lado, o evento mental, $b$ qua dor, tem essencialmente a propriedade de ser uma dor. Tome-se um mundo onde o qua objecto $b$ qua dor existe. Pelo princípio da existência, esse é um mundo onde $b$ existe e $b$ é uma dor. Mas então, pelo princípio da herança e supondo que a propriedade de ser uma dor não é formal, o qua objecto $b$ qua dor tem nesse mundo todas as propriedades que a sua base $b$ tem nesse mundo, e logo tem a propriedade de ser uma dor nesse mundo. Logo, a propriedade de ser uma dor é uma propriedade essencial do evento mental, do qua objecto $b$ qua dor. Por outro lado, é também possível representar de forma semelhante as outras ideias essencialistas utilizadas no argumento anti-materialista kripkeano, em especial a ideia de que a propriedade de ser uma estimulação das fibras-C é uma propriedade essencial do evento físico e a ideia associada de que a propriedade de ser uma dor é uma propriedade meramente contingente desse evento.

Resta-me considerar a seguinte objecção à explicação acima esboçada da distinção entre particulares físicos e mentais. A objecção é dirigida em geral contra a teoria dos qua objectos invocada na explicação e consiste na observação de que essa teoria tem a consequência absurda de contar como não identidades aquilo que são inegavelmente identidades entre particulares, como por exemplo a identidade de Véspero com Fósforo ou a identidade de Túlio com Cícero. Com efeito, parece que podemos identificar Véspero com o qua objecto Vénus qua visto ao entardecer e Fósforo com o qua objecto Vénus qua visto ao amanhecer. Como as propriedades envolvidas nas glosas são obviamente diferentes, segue-se pelo princípio da identidade que os qua objectos Vénus qua visto ao entardecer e Vénus qua visto ao amanhecer são distintos. Logo, Véspero e Fósforo são numericamente distintos, o que é claramente inaceitável. Todavia, a objecção não colhe. A razão é, naturalmente, a de que a premissa usada, a pretensão de que Véspero é identificável com o qua objecto Vénus qua visto ao entardecer e Fósforo com o qua objecto Vénus qua visto ao amanhecer, é falsa. De facto, pelo princípio da identidade, um qua objecto $x$ qua $P$ não pode ser identificado com o objecto $x$ que é a sua base; assim, dado que Véspero é Vénus, o qua objecto Vénus qua visto ao entardecer não pode ser identificado com Véspero (mutatis mutandis para Fósforo). Quando as propriedades usadas na glosa são propriedades contingentes do objectos que serve de base, é fácil verificar que qua objecto e base não podem ser objectos idênticos. Como vimos, qualquer qua objecto $x$ qua $P$ tem a propriedade modal de ser essencialmente $P$, ou seja, tem a propriedade de ser $P$ em qualquer situação contrafactual em que exista; todavia, dada a contingência da propriedade em questão, a base $\mathbf{x}$ não tem certamente essa propriedade modal. As não identidades geradas pela teoria dos qua objectos não são de todo não identidades entre objectos materiais identificados através de descrições diferentes (Véspero e Fósforo, Túlio e Cícero), mas sim não identidades entre, de um lado, objectos materiais, e, do outro, a matéria da qual eles são feitos. Por conseguinte, ao caso de objectos como Véspero e Fósforo não é possível aplicar um argumento modal do género daquele que é aplicado para estabelecer a não identidade de ESTÁTUA com BRONZE. Há certamente mundos possiveis onde o qua objecto Vénus qua visto ao entardecer existe mas onde o qua objecto Vénus qua visto ao amanhecer não existe: uma situação na qual, por qualquer razão, Vénus só é vista ao entardecer seria suficiente para o estabelecer. Todavia, daí não se segue que seja metafisicamente possível Véspero existir sem que Fósforo exista, em analogia com a possiblidade metafísica de o particular 
físico $b$ existir sem o particular mental $a$; de novo, qua objectos não podem em geral ser identificados com as suas bases.

\section{Referências}

Almog, Joseph 2002: What Am I? Descartes and the Mind-Body Problem. Oxford: Oxford University Press.

Almog, Joseph 1996: 'The What and the How II', Nous.

Almog, Joseph 1991: 'The What and the How I', Journal of Philosophy.

Block, Ned 1994: 'Functionalism'. In S. Guttenplan (ed), A Companion to the Philosophy of Mind. Oxford: Basil Blackwell, 323-32.

Chalmers, David 1996: The Conscious Mind: Oxford, Oxford University Press.

Levine, Joseph 2001: Purple Haze. Oxford: Oxford University Press.

Fine, Kit 1982: 'Acts, Events and Things'. In Language and Ontology, Proceedings of the $6^{\text {th }}$ International Wittgenstein Symposium. Vienna: Holder-Pichler-Tempsky.

Lewis, David 1994: 'Lewis, David: Reduction of Mind'. In S. Guttenplan (ed.), A Companion to the Philosophy of Mind. Oxford: Basil Blackwell, 412-31.

Nagel, Thomas 2000: 'The Psychophysical Nexus'. In P. Boghossian and C. Peacocke (eds.), New Essays on the A Priori. Oxford: Oxford University Press, 43472.

Kripke, Saul 1980: Naming and Necessity. Oxford: Basil Blackwell.

* Este ensaio foi escrito no âmbito do projecto de investigação Atitudes Proposicionais e Dinâmica Cognitiva, financiado pela Faculdade de Letras da Universidade de Lisboa. Agradeço ao Conselho Científico da FLUL pelo apoio assim dado. Uma versão abreviada foi apresentada no $1 .^{\circ}$ Encontro Nacional de Filosofia Analítica (ENFA 1), realizado em Coimbra em 17-18 de Maio de 2002. Agradeço a Teresa Marques e Manuel Garcia-Carpintero os valiosos comentários que fizeram a uma versão anterior do material. 